\title{
A computational study of the suppression of ammonia volatility in aqueous systems using ionic additives
}

\author{
Stefan Salentinig • Phil Jackson • Moetaz Attalla
}

Received: 19 February 2013/Accepted: 23 March 2013/Published online: 10 April 2013

(C) The Author(s) 2013. This article is published with open access at Springerlink.com

\begin{abstract}
Controlling vapour pressure is necessary for the viability of aqueous ammonia solutions in commercial applications such as refrigeration. In this study, Gibbs ensemble Monte Carlo (GEMC) simulations were used to calculate the vapour-liquid equilibrium (VLE) of ammonia-water- $\mathrm{MCl}$ mixtures, $M=\mathrm{Na}$ or $\mathrm{Cs}$, within the isobaric-isothermal- (NpT-) ensemble. The results indicate that in the presence of alkali metal additives, there is a non-negligible 'salting-in' effect for ammonia in the liquid phase. Experimental measurements of the liquid phase concentration of ammonia confirm the GEMC results i.e. the vapour loss rates in systems containing ionic additives is slightly lower. Gibbs ensemble Monte Carlo simulations also indicate that ammonia prefers to solvate aqueous cations as a result of electrostatic interactions. Ab-initio calculations show that the $\mathrm{M}^{+}$-ammonia complex is energetically more stable than the $\mathrm{M}^{+}$-water complex. The difference in the binding free energy $\Delta\left(\Delta G_{\text {bind }}\left(\mathrm{M}^{+}-\mathrm{NH}_{3}\right)-\Delta G_{\text {bind }}\left(\mathrm{M}^{+}-\mathrm{H}_{2} \mathrm{O}\right)\right)$ depends on the size of the cation and is highest for the smallest tight cations (e.g. $\mathrm{Li}^{+}$) and lowest for the most polarisable cations $\left(\mathrm{Cs}^{+}\right)$.
\end{abstract}

Keywords Vapour suppressing additives - Aqueous ammonia $\cdot$ Vapour liquid equilibrium · Solution structure · Gibbs ensemble Monte Carlo simulations · Ab-initio calculations

S. Salentinig $(\bowtie) \cdot$ P. Jackson $\cdot$ M. Attalla

CSIRO Energy Technology, P.O. Box 330, Newcastle,

NSW 2300, Australia

e-mail: stefan.salentinig@gmail.com

\section{Introduction}

Ammonia is a low-cost chemical, which is widely available commercially. However, its high volatility is a major concern when aqueous ammonia liquors are used in many industrial process settings e.g. ammonia based air-conditioning [1] and $\mathrm{CO}_{2}$ scrubbing from gas streams [2]. Inexpensive approaches to controlling ammonia vapour pressure could have many potential benefits, including reducing pollution/emissions and process costs. The amount of free ammonia in the gas phase above ammoniacontaining liquors is a function of temperature, pressure and other thermodynamic parameters. In the aqueous phase, the dissociation constant $\mathrm{K}_{\mathrm{b}}$ for the reaction: $\mathrm{NH}_{3}+\mathrm{H}_{2} \mathrm{O} \rightarrow \mathrm{NH}_{4}^{+}+\mathrm{OH}^{-}$is $1.774 \times 10^{-5}$ at $25^{\circ} \mathrm{C}$ i.e. ammonia is a weak base, $\mathrm{pK}_{\mathrm{b}} 4.76$ [3]. Due to this small value, it can be assumed that $\left[\mathrm{NH}_{4}{ }^{+}(\mathrm{aq})\right] \ll[\mathrm{N}-$ $\left.\mathrm{H}_{3}(\mathrm{aq})\right]$ and ammonia vapour losses will be significant except at the lowest $\mathrm{pH}$ values. Typical engineering solutions to suppress ammonia vapourisation at high $\mathrm{pH}$ involve cooling or pressurisation. However, this often has an unsatisfactory effect on operating costs, especially if refrigeration is needed in warmer climatic zones.

In this report, we explore reducing ammonia volatility via low cost alkali salt additives as an alternative to refrigeration/pressurisation. We focus on the alkali metal ion series $\mathrm{Li}^{+}-\mathrm{Cs}^{+}$for two main reasons: (i) the metal ion/ ammonia coordination number is expected to increase with increasing ion radius (from $\mathrm{Li}^{+} \rightarrow \mathrm{Cs}^{+}$), and (ii) the unidirectionality of the (mostly) electrostatic $\mathrm{M}^{+} \leftrightarrow \mathrm{NH}_{3}$ interaction is likely to be lost (and less likely to inhibit important ammonia lone-pair chemistry) as the ion radius $\left(\mathrm{M}^{+} \ldots \mathrm{NH}_{3}\right.$ separation) and solvent coordination number increase. These arguments suggest $\mathrm{Cs}^{+}$will perform better in this role than, say $\mathrm{Na}^{+}$, because less salt will be needed 
to achieve the same volatility reduction. A central goal of this study is the computational prediction of differences in the vapour-liquid equilibrium (VLE) of ammonia-water and ammonia-water-salt mixtures with the accuracy needed to assess process performance.

In the first instance, the Gibbs ensemble Monte Carlo (GEMC) method was used to investigate VLE properties of various water-ammonia- $\mathrm{MCl}$ mixtures, $M=\mathrm{Na}$, Cs. The GEMC method has previously been used for the direct determination of the phase coexistence of microfluids by Panagiotopoulos $[4,5]$. This technique makes use of distinct vapour and liquid phases. No interface between the two regions exists in the simulation and the conditions of phase coexistence are satisfied in a statistical sense.

We also aim to gain an understanding of the thermodynamics of the "salting-in" effect which could prevent ammonia escape from aqueous liquors. To the best of our knowledge, this is the first computational study of ammonia-water systems that attempts to verify this phenomenon. From the GEMC simulations, liquid and vapour densities, compositions and radial distribution functions (RDFs) for molecules in the liquid phase are generated. Radial distribution functions are used to gain insight into the bulk solution structure and the effect of ionic additives on intermolecular order. Experimental results for the hydration structures of alkali-metals in pure water show a decrease in the strength of the ion-water interaction with increasing ion size, together with a small increase in coordination number [6], consistent with our earlier points. Water shows a characteristic orientational ordering of hydrogen-bonded (H-bonded) molecules [7]. This structure is disrupted by pressure changes and chemical additives, as demonstrated by neutron scattering via changes in waterwater $\mathrm{H}-\mathrm{H}$ RDFs [8]; in this context, $\mathrm{HCl}$ was found to be less effective than other solutes (e.g. $\mathrm{NaOH}$ ) at the same concentration [9-11]. The increase of ammonia solubility in alkali-metal water solutions is also related to the nature of the interaction-chiefly electrostatic-between the ammonia molecules and alkali cations. For this reason, we have also investigated the binding free energies of $\mathrm{M}^{+}-\mathrm{X}$, $M=\mathrm{Li}-\mathrm{Cs}, X=\mathrm{NH}_{3}$ or $\mathrm{H}_{2} \mathrm{O}$, using ab-initio methods, in both the gas- and aqueous-phases.

\section{Methods}

\section{Simulations}

Thermodynamic properties of salt-ammonia-water systems were derived using the GEMC technique $[12,13]$. For the two component ammonia-water system, aggregated volume bias (AVB) steps were used [14, 15].
Pseudo-random numbers for the Monte Carlo (MC) steps were generated using DX-1597-2-7 [16]. The extended simple point-charge (SPC/E) interaction potential, which includes corrections for self-polarisation, was chosen to simulate water $[17,18]$. This model comprises three electrostatic interaction sites with an $\mathrm{OH}$ distance of $1 \AA$ and $\mathrm{HOH}$ angle of $109.471^{\circ}$. Atomic charges were set to $+0.433 \mathrm{e}$ for hydrogen atoms and $-0.848 \mathrm{e}$ for oxygen atoms [18]. For the computation of van der Waals forces between water molecules, we used a Lennard-Jones (LJ) interaction potential centred on the oxygen atom (see Eq. 1).

Interactions within, and between, ammonia molecules are described by the optimised potential for liquid simulation-all atoms (OPLS-AA) force field with a charge of $-1.02 \mathrm{e}$ for nitrogen, and charges of $0.34 \mathrm{e}$ for hydrogen [19]. This force field has also been shown to work well within the SPC/E model [20]. For cations and anions, the Aqvist and LGM force fields were used, respectively [21, 22].

Non-bonded interactions are represented by an LJ plus Coulomb term as shown in Eq. 1:

$E=\sum_{i} \sum_{j>i}\left\{\frac{q_{i} q_{j}}{4 \pi \varepsilon_{0} r_{i j}}+4 \varepsilon_{i j}\left[\left(\frac{\sigma_{i j}}{r_{i j}}\right)^{12}-\left(\frac{\sigma_{i j}}{r_{i j}}\right)^{6}\right]\right\}$

where $q$ is the charge of the atom, $r$ is the distance between the interaction centres, $\varepsilon$ the depth of the potential well and $\sigma$ the distance at which the potential reduces to zero. $i$ and $j$ define different interaction centres. Geometrical mixing rules were applied throughout this study for the determination of $\mathrm{LJ}$ parameters for different atoms as shown in Eqs. 2 and 3:

$\sigma_{i j}=\sqrt{\sigma_{i i} \sigma_{j j}}$

$\varepsilon_{i j}=\sqrt{\varepsilon_{i i} \varepsilon_{j j}}$

An $11 \AA$ cut-off with analytical tail correction was applied throughout [23]. Coulombic interactions were determined using the Ewald sum method with a cut-off radius adjusted to half the box length [23, 24].

Cubic boxes with periodic boundary conditions were used for the liquid and vapour phases. Molecules were partitioned such that approximately two thirds were placed in the liquid box and the remainder in the vapour box. The total number of particles in the simulations was 404 , consisting of 360 water-, 40 ammonia-, two cations and two anions. The simulations were performed at a constant pressure of $101.3 \mathrm{kPa}$ over the temperature range 273-400 K. All simulations were run until quasi-equilibrium was achieved (between 100,000 and 300,000 MC cycles). Each MC cycle involves $N$ steps, $N=$ total number of molecules. Values were recorded during the production period of 50,000-100,000 cycles. The standard deviations for all results were calculated by breaking the production period into five blocks. 
To sample phase space, four different kinds of MC steps have been assigned: constant pressure volume steps [25], inter-box and intra-box swap steps [12, 13], translations of the centre-of-mass of the molecules and rotation around the centre-of-mass. The corresponding probabilities were 1, $14,15,37$ and $33 \%$, respectively. The mole fraction of salt in the vapour phase was fixed at zero. In the ammoniawater two-component system, an additional aggregated volume bias step $[14,15]$ has been assigned with a probability of $3 \%$ on cost of the translation of the centre-ofmass. The maximum displacement of molecules during rotational and translational steps was adjusted to yield acceptance rates of $50 \%$ in all simulations.

Version 7.0.2 of the MCCCS Towhee source code was used throughout this study [26]. Calculations with Towhee were performed on an IBM System x iDataplex dx360 M3 cluster system running Linux. The cluster consists of 146 compute nodes, each with dual 6-core Intel Xeon Westmere cores with $12 \mathrm{MB}$ cache-a total of 1,752 cores. The node interconnect is quad data rate (QDR) Infiniband. The system is housed at CSIRO Advanced Scientific Computing in Docklands, Melbourne, Australia.

\section{Ab-initio calculations}

For a systematic study of the influence of cation-size on the strength of the $\mathrm{M}^{+}-\mathrm{NH}_{3}$ interactions, $\Delta G_{298}\left(\mathrm{M}^{+}-\right.$ $\mathrm{NH}_{3} \rightarrow \mathrm{M}^{+}+\mathrm{NH}_{3}$ ) for $M=\mathrm{Li}-\mathrm{Cs}$ has been calculated. The composite G4 method was used to determine the strength of interaction for $M=\mathrm{Li}-\mathrm{K}[27,28]$. These calculations were performed with the G09 software suite [29]. For Li-Cs, interaction free energies were calculated with GAMESS software [30] using a hybrid-meta density functional and an effective core potential - triple zeta basis set combination: M06-2X/RECP-TZVPPD [31]. This approach explicitly includes the outer nine valence electrons of $\mathrm{Cs}^{+}$and $\mathrm{Rb}^{+}$via the augmented triple-zeta basis set $[30,32]$. The $\mathrm{Li}^{+}-\mathrm{NH}_{3}, \mathrm{Na}^{+}-\mathrm{NH}_{3}$ and $\mathrm{K}^{+}-\mathrm{NH}_{3}$ system binding energies were evaluated using both the composite G4 and M06-2X methods to compare the accuracy of the density functional theory (DFT) values: excellent agreement $\left(\left|\Delta G_{\mathrm{G} 4}-\Delta G_{\mathrm{M} 06-2 \mathrm{X}}\right|<2 \%\right)$ was found (see Table 1). The electronic energies in solution were calculated at the SM6 + M06-2X/TZVPPD level, using redistributed Löwdin population analysis (RLPA) charges [33] and the following Bondii radii [34]: $K=2.75 \AA$, Na $=2.27 \AA$, $\mathrm{Li}=1.82 \AA$ [35]. State corrections for the free energy change of $1 \mathrm{~mol}$ of an ideal gas from 1 atm $\left(24.4 \mathrm{~L} \mathrm{~mol}^{-1}\right)$ to $1 \mathrm{~mol} \mathrm{~L}^{-1} \Delta G^{0 \rightarrow *}$ were calculated with Eq. $4[35,36]$.

$\Delta G^{0 \rightarrow *}=R T \ln (24.4)$.

with $R$ being the ideal gas constant and $T=298 \mathrm{~K}$. Solvation free energies were calculated using the
GAMESSPLUS software [37] and-in the case of hydrated cations-were also adjusted for the change in water concentration, $R T \ln (55.34)$, as described by Goddard [38]. Abinitio calculations were performed on the sun constellation cluster 'vayu' housed at the NCI National Facility at ANU, Canberra, Australia. This system consists of 1,492 nodes in Sun X6275 blades, each containing two quad-core $2.93 \mathrm{GHz}$ Intel Nehalem cpus with 6.4GTs QPI bus and a total of $37 \mathrm{~TB}$ of RAM on the computer nodes.

\section{Experiments}

Methods

Density measurements were performed using an Anton Paar DMA 38 digital benchtop density meter. The accuracy for density measurements with this device is $0.001 \mathrm{~g} / \mathrm{ml}$ over the temperature range $288-313 \mathrm{~K}$. For concentration measurements of ammonia in the liquid phase, calibration curves were recorded. Five different ammonia concentrations between 0 and $10 \%$ were measured, and linear regression was used to correlate the liquid density to the ammonia concentration in the ammonia-water and $\mathrm{NaCl}-$ ammonia-water systems. The concentration of $\mathrm{NaCl}$ was $0.5 \mathrm{~mol} \%$ which yields a mole ratio of $\mathrm{NaCl}: \mathrm{NH}_{3}$ of $\sim 1: 20$. For the experimental study of ammonia evaporation, $20 \mathrm{~mL}$ of each solution was heated to $323 \mathrm{~K}$ in water bath. At defined time-steps, $1 \mathrm{~mL}$ samples were taken with a syringe and immediately injected into the sample cell of the density meter. The density value was recorded after the temperature of the sample equilibrated within the cell (to $293 \mathrm{~K})$.

\section{Materials}

Ammonium hydroxide solution ACS reagent, 28-30 \% $\mathrm{NH}_{3}$ base was purchased from Sigma-Aldrich. The salts used in this study were $\mathrm{CsCl}, 99.9 \%$, and $\mathrm{NaCl}$ (BioXtra, $\geq 99.5 \%$ ) from Sigma-Aldrich. Milli-Q water $(R>18 \mathrm{M} \Omega)$ was used throughout.

\section{Results}

Calculated density values from GEMC simulations are presented in Fig. 1 for the liquid (Fig. 1a) and vapour phase (Fig. 1b). Experimentally measured density values for the liquid phase from 293 to $313 \mathrm{~K}$ are also presented. Over this temperature range, simulated values are in excellent agreement with the experimental values. In addition, the ammonia-water system exhibits a maximum in density around $290 \mathrm{~K}$ and both the $\mathrm{NaCl}$ and $\mathrm{CsCl}$ 
Table 1 Results from ab-initio calculations using M06-2X/TZVPPD, M06-2X/RECP-TZVPPD and the composite G4 method (values in brackets): The self consistent field (SCF) energies, bonding length,
Gibbs free energy for the dissociation reaction at $298 \mathrm{~K}\left(\Delta G_{298}\right)$, $\mathrm{M}^{+}-\mathrm{X} \rightarrow \mathrm{M}^{+}+\mathrm{X}\left(\mathrm{M}^{+}=\mathrm{Li}^{+}\right.$to $\mathrm{Cs}^{+}, X=\mathrm{NH}_{3}$ or $\left.\mathrm{H}_{2} \mathrm{O}\right)$ and the total electronic energy including the zero-point energy $(\mathrm{V}(0 \mathrm{~K}))$

\begin{tabular}{|c|c|c|c|c|c|c|}
\hline $\mathrm{M}^{+}-\mathrm{X}$ & $\begin{array}{l}\text { SCF energies } \\
\text { [hartree] }\end{array}$ & $\begin{array}{l}\mathrm{r}_{\mathrm{M}-\mathrm{NH} 3}(\mathrm{~g}) \\
{[\AA]}\end{array}$ & $\begin{array}{l}\mathrm{r}_{\mathrm{M}-\mathrm{NH} 3}(\mathrm{aq}) \\
{\left[\AA \AA^{\mathrm{A}}\right]}\end{array}$ & $\begin{array}{l}\mathrm{V}(0 \mathrm{~K}) \\
{\left[\mathrm{kJ} \mathrm{mol}{ }^{-1}\right]}\end{array}$ & $\begin{array}{l}\Delta G_{298}(\mathrm{~g}) \\
{\left[\mathrm{kJ} \mathrm{mol}^{-1}\right]}\end{array}$ & $\begin{array}{l}\Delta G_{298}(\mathrm{aq}) \\
{\left[\mathrm{kJ} \mathrm{mol}^{-1}\right]}\end{array}$ \\
\hline $\mathrm{Li}^{+}$ & -7.282887 & & & & & \\
\hline $\mathrm{Na}^{+}$ & -162.057486 & & & & & \\
\hline $\mathrm{K}^{+}$ & -599.742719 & & & & & \\
\hline $\mathrm{Rb}^{+}(+\mathrm{ECP})$ & -23.8719249 & & & & & \\
\hline $\mathrm{Cs}^{+}(+\mathrm{ECP})$ & -19.934155 & & & & & \\
\hline $\mathrm{NH}_{3}$ & -56.553818 & & & & & \\
\hline $\mathrm{H}_{2} \mathrm{O}$ & -76.431951 & & & & & \\
\hline $\mathrm{Li}^{+}-\mathrm{NH}_{3}$ & -63.901811 & 1.968 (1.968) & 1.975 & $162(158)$ & $136(132)$ & 97 \\
\hline $\mathrm{Li}^{+}-\mathrm{H}_{2} \mathrm{O}$ & -83.771629 & 1.820 & 1.856 & 142 & 117 & 79 \\
\hline $\mathrm{Na}^{+}-\mathrm{NH}_{3}$ & -218.656946 & $2.336(2.336)$ & 2.326 & 113 (112) & $88(87)$ & 73 \\
\hline $\mathrm{Na}^{+}-\mathrm{H}_{2} \mathrm{O}$ & -238.529068 & 2.195 & 2.221 & 99 & 74 & 57 \\
\hline $\mathrm{K}^{+}-\mathrm{NH}_{3}$ & -656.328267 & $2.756(2.761)$ & 2.743 & 77 (76) & $54(52)$ & 56 \\
\hline $\mathrm{K}^{+}-\mathrm{H}_{2} \mathrm{O}$ & -676.203346 & 2.603 & 2.604 & 71 & 48 & 45 \\
\hline $\mathrm{Rb}^{+}-\mathrm{NH}_{3}$ & -80.4535967 & 2.942 & & 68 & 44 & \\
\hline $\mathrm{Rb}^{+}-\mathrm{H}_{2} \mathrm{O}$ & -100.329317 & 2.778 & & 62 & 39 & \\
\hline $\mathrm{Cs}^{+}-\mathrm{NH}_{3}$ & -76.513027 & 3.114 & & 61 & 37 & \\
\hline $\mathrm{Cs}^{+}-\mathrm{H}_{2} \mathrm{O}$ & -96.389118 & 2.949 & & 56 & 34 & \\
\hline
\end{tabular}

containing systems exhibit maximum vapour densities around $300 \mathrm{~K}$. At higher temperatures (up to $400 \mathrm{~K}$ ), the densities of all systems are reduced.

The liquid-phase concentration of ammonia derived from GEMC simulations is presented in Fig. 2. In the presence of $\mathrm{NaCl}$ and $\mathrm{CsCl}$, an increase in the concentration of ammonia (ammonia:water molar ratio) is evident. No difference between the two salts could be observed within the accuracy of the method.

The experimental Gibbs free energy of solvation of ammonia is the difference between the free energy of formation in the aqueous phase and in the gas phase: $\Delta G_{\mathrm{s}}=\Delta G_{\mathrm{f}, \mathrm{aq}}^{0}-\Delta G_{\mathrm{f}}^{0}=-10.1 \mathrm{~kJ} \mathrm{~mol}^{-1}$ at $298.15 \mathrm{~K}$ and $100 \mathrm{kPa}$ [3]. The value obtained from the GEMC simulations is $-10.8 \mathrm{~kJ} \mathrm{~mol}^{-1}$ at $295 \mathrm{~K}$ and $101.3 \mathrm{kPa}$, which is in good agreement with the literature value. The Gibbs free energy of transfer from the gas to the liquid phase was calculated from GEMC simulations at several different temperatures and is presented in Fig. 3. Lower Gibbs free energies were observed in the salt containing system.

To validate the GEMC findings of ammonia vapour suppression, measurements of ammonia concentration as a function of time in an open vessel $(T=323 \mathrm{~K})$ were performed. The results are presented in Fig. 4. The curves reveal a relative decrease in ammonia concentration in the liquid phase in the presence of $0.5 \mathrm{~mol} \% \mathrm{NaCl}$.
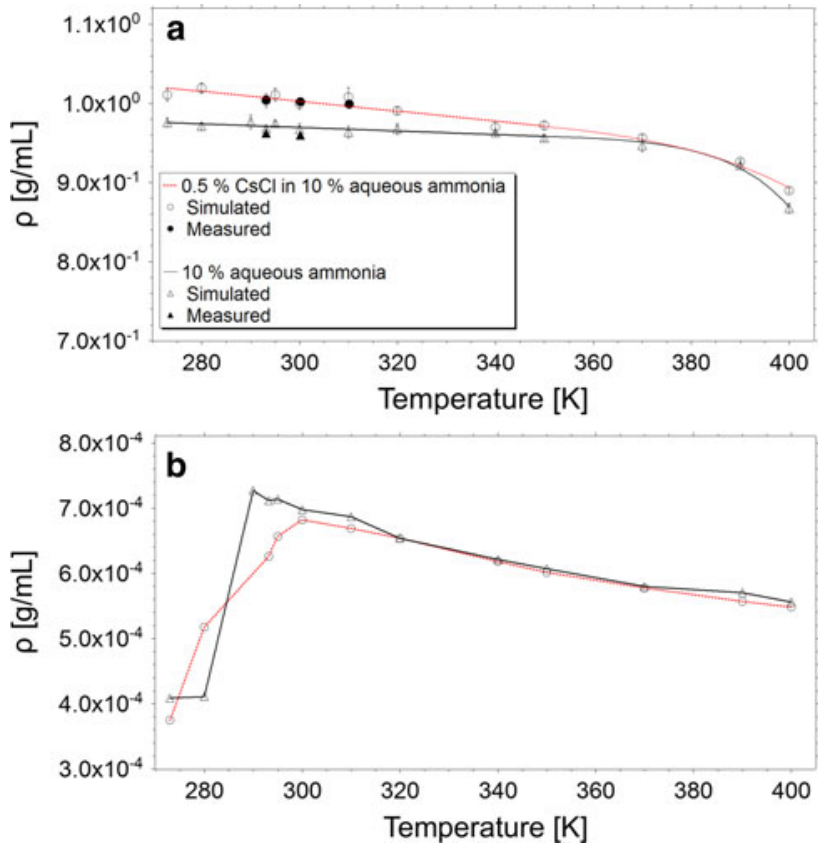

Fig. 1 Densities as a function of temperature of $10 \mathrm{~mol} \%$ ammoniawater system and the same system containing $0.5 \mathrm{~mol} \% \mathrm{CsCl}$ in the liquid (a) and vapour phase (b) at $101.3 \mathrm{kPa}$. Open triangles and full black line represent the ammonia-water system and points and dashed red line the $\mathrm{CsCl}$-ammonia-water system. Full symbols represent experimentally measured values at the same composition. The connecting lines have been plotted as a guide for the eye 


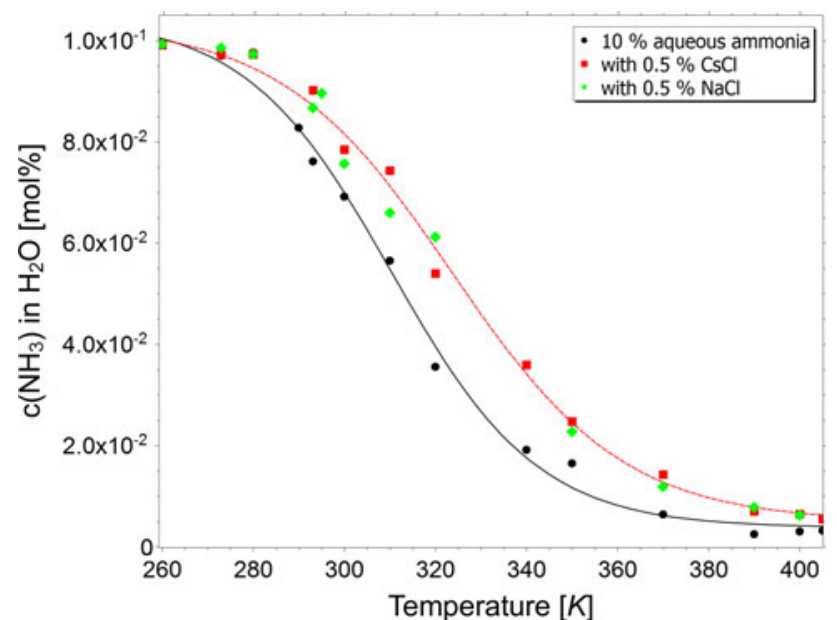

Fig. 2 Concentration of ammonia in the liquid phase depending on temperature at $101.3 \mathrm{kPa}$ from GEMC simulations. Black points represent the $10 \mathrm{~mol} \%$ ammonia-water system. Red squares and green diamonds show the $10 \mathrm{~mol} \%$ ammonia-water system containing $0.5 \mathrm{~mol} \% \mathrm{CsCl}$ and $\mathrm{NaCl}$, respectively. The lines are a guide for the eye obtained by fitting exponential decays to the data points

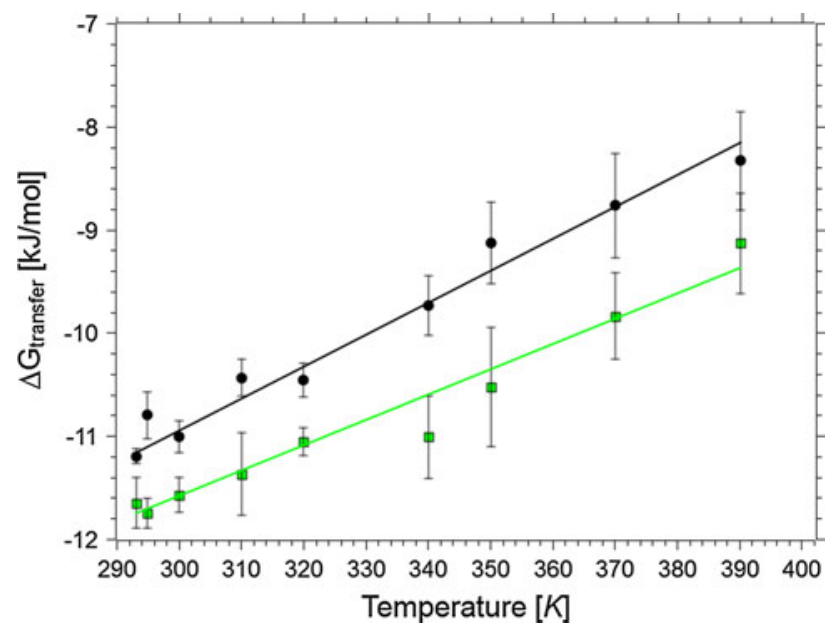

Fig. 3 Temperature dependence of the Gibbs free energy of transfer from the gas to the liquid phase $\left(\Delta G_{\text {transfer }}\right)$ from GEMC simulations of $10 \%$ ammonia in water (black circles) and $10 \%$ ammonia in water containing $0.5 \mathrm{~mol} \% \mathrm{NaCl}$-water (green squares) at $101.3 \mathrm{kPa}$. The lines are linear fits to the simulated data points and should be a guide for the eye

The influence of ions on the H-bonding network in the ammonia-water system has been investigated by calculating the RDFs for $\mathrm{H}-\mathrm{H}$ interactions in water for the liquid box at $293.15 \mathrm{~K}$. The RDF for ammonia-water presented in Fig. 5a exhibits three peaks near 2.4, 3.9 and $4.7 \AA$. The peak positions for the RDFs are consistent with those extracted from neutron scattering curves for pure water [7] (plotted in the same graph) and represent the strong orientational ordering within the $\mathrm{H}$-bonded water network. After addition of $0.5 \mathrm{~mol} \% \mathrm{NaCl}$ or $\mathrm{CsCl}$, the height of the first and second peaks increases by about $10 \%$ and the

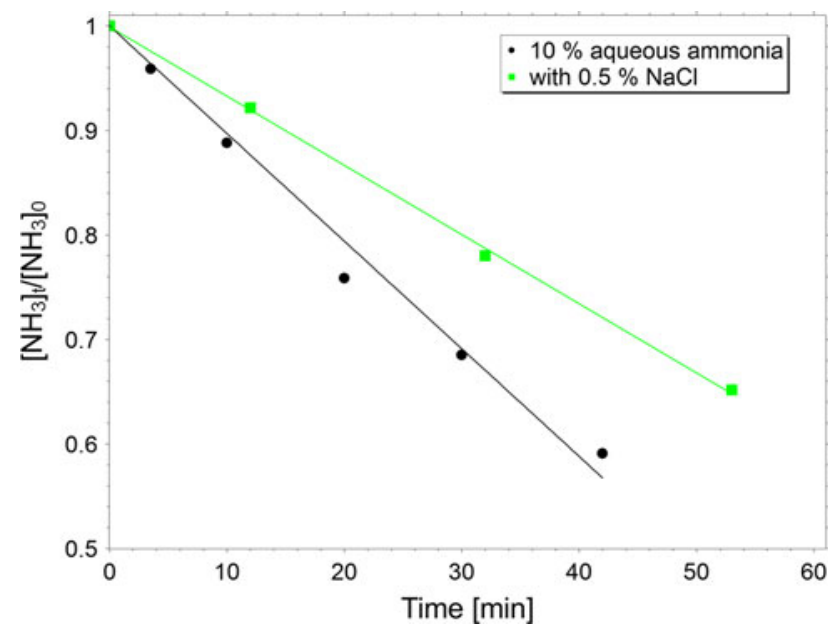

Fig. 4 Experimental measurements of the liquid phase ammonia concentration during evaporation of ammonia from a $10 \mathrm{~mol} \%$ ammonia in water sample with time at $50{ }^{\circ} \mathrm{C}$ and $101.3 \mathrm{kPa}$. The full black points and full black line represent the ammonia-water system and the green squares and the green line the $\mathrm{NaCl}$-ammonia-water system. The lines are linear fits to the data-points to guide the reader

third peak at $4.7 \AA$ diminishes. This indicates that the number of water molecules in the first and second solvation shell of water increases in the presence of ions; yet, the average distance of the orientational interactions in the H-bonded network decreases, and this is evident by the loss of the third order peak.

A plot of the RDFs for (water) oxygen-atoms surrounding $\mathrm{Na}^{+}$and (ammonia) nitrogen-atoms surrounding $\mathrm{Na}^{+}$is presented in Fig. 5b. Both water and ammonia are present in the first solvation shell of $\mathrm{Na}^{+}$. The extent of the first solvation shell for both $\mathrm{O}$ and $\mathrm{N}$ is $2.49 \AA$. This value is in good agreement with the optimised bond lengths from ab-initio calculations shown in Table 1 and also consistent with experimental data for (water) oxygen-atoms around $\mathrm{Na}^{+}$derived from X-ray and neutron scattering [39, 40].

Representative snapshots of the liquid- and vapour box for ammonia-water and $\mathrm{NaCl}-$ ammonia-water at $293.15 \mathrm{~K}$ and $101.3 \mathrm{kPa}$ are presented in Fig. 6. For the salt-containing systems, there is a clear reduction in the number of vapour phase ammonia molecules. The distribution diagram of ammonia molecules within the liquid simulation box of the $\mathrm{NaCl}$-ammonia-water system at two temperatures ( 293.15 and $370 \mathrm{~K}$ ) is presented in Fig. 7. The box-dimensions have been normalised to simplify comparison. Fig. 7a shows that ammonia prefers to be selfsolvated, or surrounded by other ammonia molecules; the extent of self-solvation decreases at higher temperatures (e.g. $370 \mathrm{~K}$ in Fig. 7b). From these distributions, it is also clear that ammonia molecules do not necessarily accumulate near $\mathrm{Na}^{+}$or $\mathrm{Cl}^{-}$ions (located in the corners of the liquid box) but are almost evenly distributed throughout the $(\mathrm{x}, \mathrm{y})$ area. 


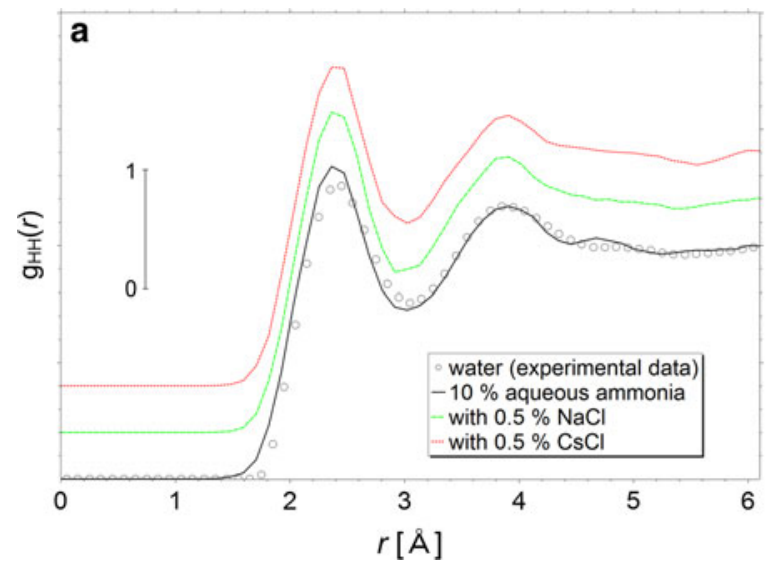

Fig. 5 a Water-water H-H RDFs: The scatters are experimental data from neutron scattering experiments on water taken from [7], the full black line is derived from the GEMC simulations of $10 \mathrm{~mol} \%$ ammonia in water, $0.5 \mathrm{~mol} \% \mathrm{NaCl}$ in ammonia-water (dashed green line) and $0.5 \mathrm{~mol} \% \mathrm{CsCl}$ in ammonia-water system (dashed red line).

The values for the binding energies of $\mathrm{M}^{+}-\mathrm{X}, M=\mathrm{Li}-\mathrm{Cs}$ $X=\mathrm{NH}_{3}$ or $\mathrm{H}_{2} \mathrm{O}$, are presented in Table 1 alongside the $\mathrm{M}^{+}-\mathrm{NH}_{3} / \mathrm{H}_{2} \mathrm{O}$ optimised bond lengths (M06-2X/(RECP)TZVPPD calculations; values obtained using the composite G4 method for $\mathrm{M}^{+}=\mathrm{Li}-\mathrm{K}$ are given in brackets. Optimisations in the dielectric continuum (SM6 + M06-2X/ TZVPPD, $\mathrm{M}^{+}=\mathrm{Li}-\mathrm{K}$ ) were used to generate the corresponding aqueous values. The equilibrium constants for the dissociation reaction $\mathrm{M}^{+}-\mathrm{X} \rightarrow \mathrm{M}^{+}+\mathrm{X}$ (Table 2) from the standard Gibbs thermodynamic relation:

$K_{\mathrm{eq}}=e^{-\frac{\Delta G_{\mathrm{R}}}{R T}}$

show that equilibrium clearly lies towards the $\mathrm{M}^{+}-\mathrm{X}$ complex and $\mathrm{M}^{+}-\mathrm{NH}_{3}$ is preferred to $\mathrm{M}^{+}-\mathrm{H}_{2} \mathrm{O}$ in the gasand aqueous phase.

The binding energy differences between ammonia and water complexes for a specific cation: $\Delta \Delta G\left(\mathrm{M}^{+}-\mathrm{X} \rightarrow\right.$ $\left.\mathrm{M}^{+}+\mathrm{X}\right)$ in both the gas- and aqueous phases are plotted in Fig. 8a. The ion-ammonia binding energies are consistently larger than corresponding ion-water values.

A log-log plot of the gas-phase binding free energy of $\mathrm{M}^{+}-\mathrm{NH}_{3}$ versus $\mathrm{r}_{\mathrm{M}-\mathrm{NH}_{3}}$ derived from DFT calculations is presented in Fig. 8b. The linearity of the graph demonstrates an approximate third order distance-dependence for the $\mathrm{M}^{+}-\mathrm{NH}_{3}$ interaction potential.

\section{Discussion}

Gibbs ensemble Monte Carlo simulations have been used to gain insight into intermolecular interactions between alkali metal ions and ammonia in aqueous solutions. The quality of simulated densities of ammonia-water and saltammonia-water liquid phases was the basis for force-field

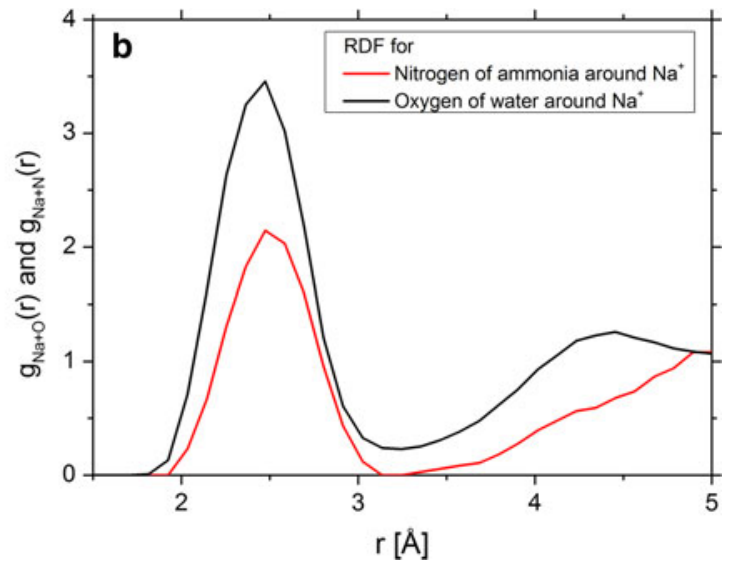

The curves have been shifted by constant values for better visibility. b Comparison between the radial distribution functions (RDF) for $\mathrm{Na}^{+}$and oxygen atoms in water (black line) and $\mathrm{Na}^{+}$and nitrogen atoms in ammonia (red line) for $10 \mathrm{~mol} \%$ ammonia in water containing $0.5 \mathrm{~mol} \% \mathrm{NaCl}$ at $293.15 \mathrm{~K}$ and $101.3 \mathrm{kPa}$

selection. Densities were remeasured experimentally and show quantitative agreement with the simulation results. In general, all systems demonstrate a decrease in density with increasing temperature. The change of density with temperature is predominantly due to the following effects: (i) increased molecular motions which weaken the H-bonding network $\rightarrow$ density decrease, and (ii) evaporative ammonia losses $\rightarrow$ density increase. All systems (with or without added cations) exhibit decreasing density with increasing temperature, indicating that thermal effects are dominant. However, the simulations also show that in solution, density decreases more slowly with increasing temperature in the presence of salt cations. This suggests that less ammonia will evaporate when salts are present and thus the ammonia solubility in the liquid phase is higher at higher temperatures, albeit only slightly. Similarly, the mole ratio of ammonia in water as a function of temperature also indicates higher ammonia solubility in the aqueous phase resulting from a 'salting-in' effect. This trend could also be confirmed experimentally through measurements of lower ammonia evaporation rates in the presence of $\mathrm{NaCl}$. To further investigate the effect of alkali-metal salts on the vapour liquid equilibrium, the Gibbs free energy of transfer from the gas to the liquid phase was calculated from GEMC simulations at several different temperatures. Lower Gibbs free energies of solvation were derived from GEMC simulations at several different temperatures. Lower solvation free energies were observed in the salt containing system, which implies a higher solubility of ammonia in the aqueous phase and consequently a lower ammonia vapour pressure.

From an intermolecular point of view, addition of $\mathrm{NaCl}$ and $\mathrm{CsCl}$ alters the structure of the solvent $\mathrm{H}$-bond network. Ammonia is displaced from the water-water H-bonded 

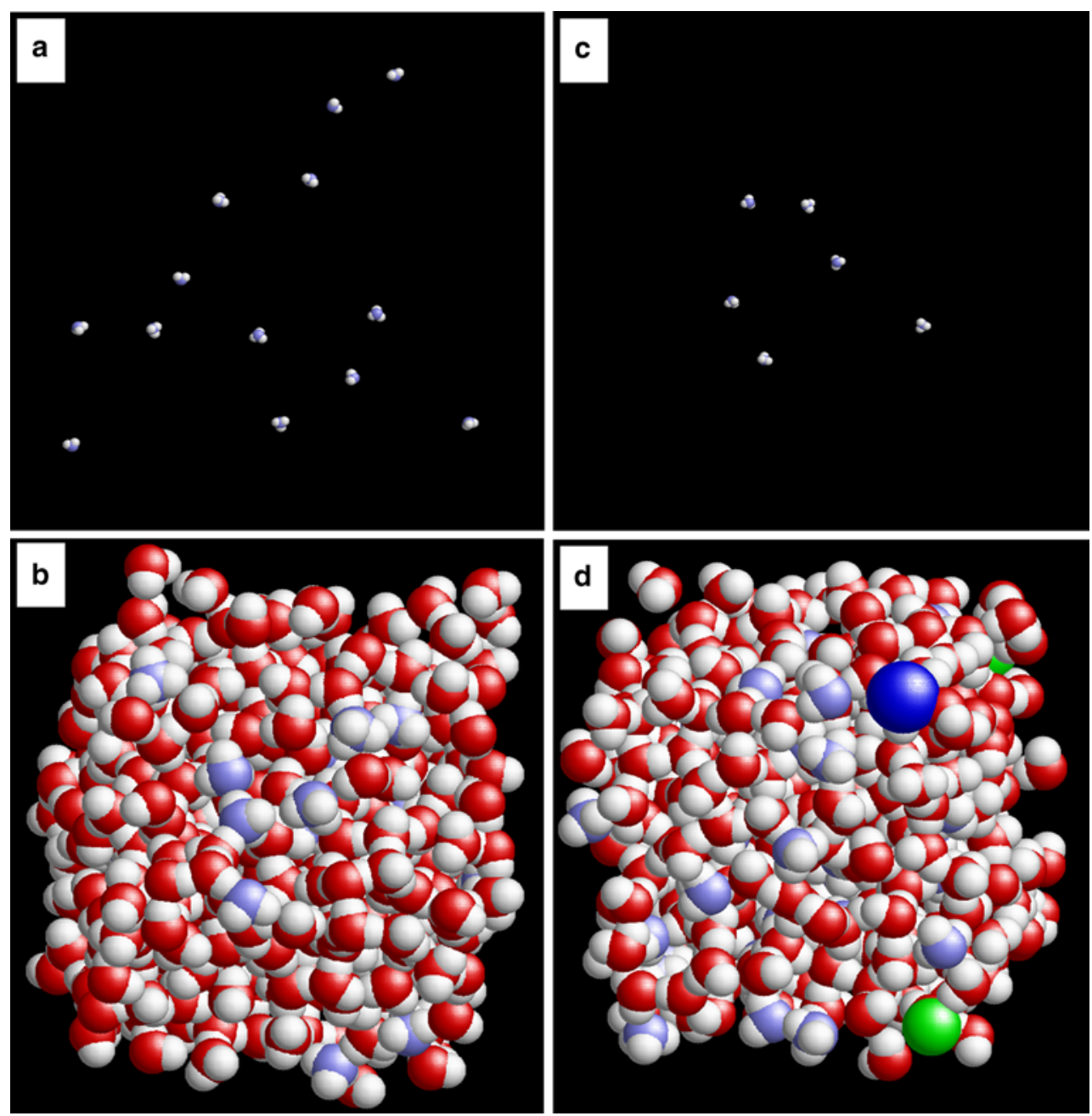

Fig. 6 Representative snapshots from the GEMC simulation at $293.15 \mathrm{~K}$ and $101.3 \mathrm{kPa}$ for the vapour- (a) and liquid phase (b) at $10 \mathrm{~mol} \%$ aqueous ammonia, and the vapour- (c) and liquid phase

network towards the aqueous $\mathrm{Na}^{+}$and $\mathrm{Cs}^{+}$ions. An increase in the water-water coordination number and a denser $\mathrm{H}$-bonding network between water molecules is a direct consequence. No increase in the ammonia molecule density around the $\mathrm{Cl}^{-}$counterions was evident. Electrostrictive effects influence the coordination of water molecules which could possibly decrease the length-scale of interactions within the hydrogen-bonded network.

The preferential solvation of $\mathrm{Na}^{+}$and $\mathrm{Cs}^{+}$by ammonia is supported by the strength of the electrostatic interactions between alkali-metals and ammonia, as determined using ab-initio calculations: The $\mathrm{M}^{+}-\mathrm{NH}_{3}$ complex is preferred over $\mathrm{M}^{+}-\mathrm{H}_{2} \mathrm{O}$ for $M=\mathrm{Li}-\mathrm{Cs}$. This is evident from the binding energies given in Table 1 as well as the corresponding reaction equilibrium constants presented in Table 2. Systematic investigation of the interactions between alkali-metal cations and both ammonia and water showed a decrease in the potential with increasing cation

(d) at $0.5 \mathrm{~mol} \% \mathrm{NaCl}$ in $10 \mathrm{~mol} \%$ aqueous ammonia. Oxygen atoms are in red, hydrogen in gray, nitrogen in violet, sodium in blue and chloride in green

size from $\mathrm{Li}^{+}$to $\mathrm{Cs}^{+}$in the gas- and aqueous phase. The decrease is more pronounced in the $\mathrm{M}^{+}-\mathrm{NH}_{3}$ system due to a stronger $\mathrm{Li}^{+} / \mathrm{NH}_{3}$ interaction. For instance, the Gibbs free energy of the dissociation reaction for gas-phase ammonia complexes decreases from 136 to $37 \mathrm{~kJ} \mathrm{~mol}^{-1}$, whereas the values for water decrease from 117 to $34 \mathrm{~kJ} \mathrm{~mol}^{-1}$. A possible explanation for this might be the molecular polarisability of ammonia $\left(2.21 \AA^{3}\right)$, which is higher than that of water $\left(1.43 \AA^{3}\right)$. The ion dipole potential can be written as $[41,42]$ :

$V_{\mathrm{id}} \cong-\frac{\alpha q^{2}}{2 r^{4}}-\frac{\mu_{\mathrm{D}} q}{r^{2}}$

where $r$, radial distance of the solvent molecule from the point-positive charge, $\alpha$, solvent polarisability, $\mu_{\mathrm{D}}$, solvent dipole moment and $q$, electron charge. The variation of the ion-dipole potential with distance separation is most favourable for ammonia up to around $2.1 \AA$. At larger 
Fig. 7 Distribution density of the ammonia-nitrogen atom at $101.3 \mathrm{kPa}$ and $T=293.15$ (a) and $370.00 \mathrm{~K}(\mathbf{b})$ in the horizontal $x y$ plane of the liquid simulation box. The box dimensions $\mathrm{x}$ and $\mathrm{y}$ are normalised to one. The probability of finding ammonia at a certain position is represented by colours from black (0) to yellow (maximum)
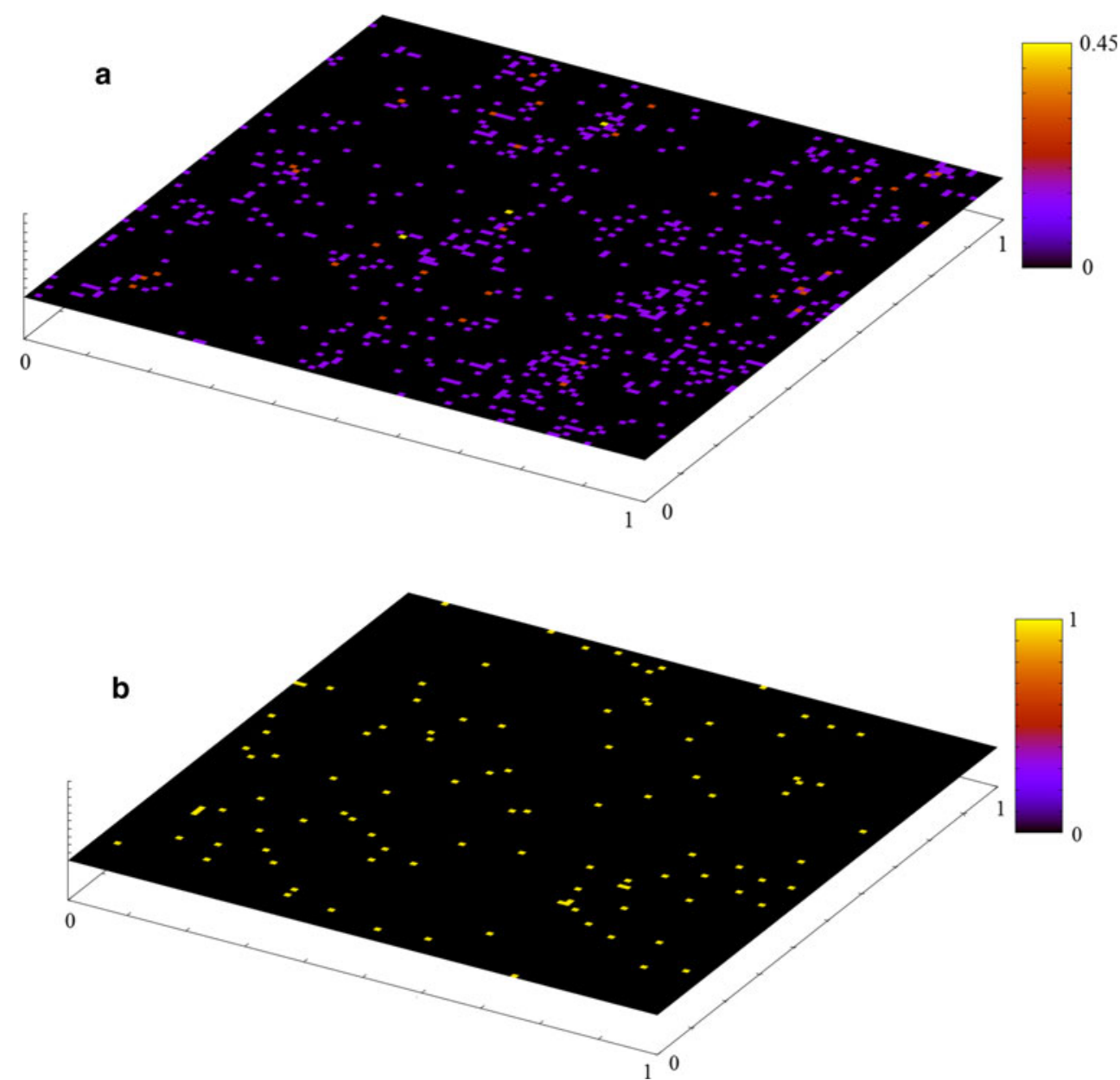

Table 2 Equilibrium constants for the reaction $\mathrm{M}^{+}-\mathrm{X} \rightarrow \mathrm{M}^{+}+\mathrm{X}$ calculated from the reaction free energy presented in Table 1 at $T=298 \mathrm{~K}$

\begin{tabular}{lll}
\hline $\mathrm{M}^{+}-\mathrm{X}$ & $K_{\text {eq }}(\mathrm{g})$ & $K_{\text {eq }}(\mathrm{aq})$ \\
\hline $\mathrm{Li}^{+}-\mathrm{NH}_{3}$ & $1.48 \mathrm{E}-24$ & $1.01 \mathrm{E}-17$ \\
$\mathrm{Li}^{+}-\mathrm{H}_{2} \mathrm{O}$ & $3.17 \mathrm{E}-21$ & $1.44 \mathrm{E}-14$ \\
$\mathrm{Na}^{+}-\mathrm{NH}_{3}$ & $3.82 \mathrm{E}-16$ & $1.62 \mathrm{E}-13$ \\
$\mathrm{Na}^{+}-\mathrm{H}_{2} \mathrm{O}$ & $1.08 \mathrm{E}-13$ & $1.03 \mathrm{E}-10$ \\
$\mathrm{~K}^{+}-\mathrm{NH}_{3}$ & $3.46 \mathrm{E}-10$ & $1.54 \mathrm{E}-10$ \\
$\mathrm{~K}^{+}-\mathrm{H}_{2} \mathrm{O}$ & $3.89 \mathrm{E}-09$ & $1.31 \mathrm{E}-08$ \\
$\mathrm{Rb}^{+}-\mathrm{NH}_{3}$ & $1.95 \mathrm{E}-08$ & \\
$\mathrm{Rb}^{+}-\mathrm{H}_{2} \mathrm{O}$ & $1.47 \mathrm{E}-07$ & \\
$\mathrm{Cs}^{+}-\mathrm{NH}_{3}$ & $3.29 \mathrm{E}-07$ & \\
$\mathrm{Cs}^{+}-\mathrm{H}_{2} \mathrm{O}$ & $1.10 \mathrm{E}-06$ & \\
\hline
\end{tabular}

separations, the second term of Eq. 6 begins to dominate. Since the dipole moment of water is larger than the dipole moment of ammonia, the potential of interaction becomes more favourable for water beyond $2.1 \AA$. Note that Eq. 6 assumes dipole 'locking' parallel to the $\mathrm{M}^{+}-\mathrm{NH}_{3}$ bond $\left(\cos 0^{\circ}=1\right)$. The DFT binding energies (which capture higher order attractive terms) are plotted in a log-log plot and exhibit a distance dependence of $r^{-3}$, an order of magnitude smaller than a pure ion-dipole interaction, but larger than the ion-polarisability interaction in Eq. 6.

The decrease in binding energy with increasing cation radius which is predicted by the DFT calculations is not apparent in the VLE data simulations. Both $\mathrm{Na}^{+}$and $\mathrm{Cs}^{+}$ have a comparable effect on the increase in ammonia solubility-within the accuracy of our simulations. This suggests that: (i) the effect is too small to be observed with sub-molar additive concentrations, or (ii) there is an alteration of the local water structure that causes stronger ammonia-water interactions down the group. It is presumed throughout that the $\mathrm{M}^{+}-\mathrm{NH}_{3}$ versus $\mathrm{M}^{+}-\mathrm{H}_{2} \mathrm{O}$ binding free energies will predict favourable solute-solute interactions via a preference for ammonia solvation rather than water; expanding the solvation shell and treating more solvating molecules explicitly at the quantum level is necessary for the most accurate picture.

Distribution densities of ammonia within the liquid GEMC simulation box suggest micro-aggregation of ammonia molecules. This means that ammonia molecules 


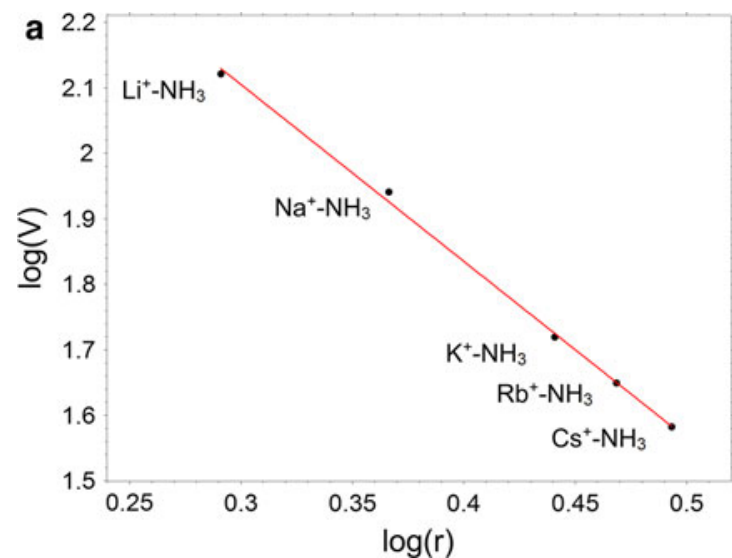

Fig. 8 a $\mathrm{Log}-\log$ plot of the binding energy $(\mathrm{V}[\mathrm{kJ} / \mathrm{mol}])$ versus the $\mathrm{M}^{+}-\mathrm{NH}_{3}$ bond length $(r[\AA])$ for $\mathrm{M}^{+}=\mathrm{Li}^{+}$to $\mathrm{Cs}^{+}$to a single ammonia molecule at $298 \mathrm{~K}$. The full line is a linear fit to the data with a slope of -3 . b Difference in the Gibbs free energy $\left(\Delta \Delta G_{298}\right)$

tend to self-solvate whereas water forms tetrahedral aggregates which can exclude ammonia. At higher temperatures, mixed ammonia-water clusters predominate. A similar behaviour has been found for alcohol-water mixtures [43]. As suggested by the results presented here, some of the ammonia will preferentially solvate the cations in the aqueous phase.

\section{Conclusion}

Suppressing ammonia vapourisation from aqueous ammonia solutions is important for many processes e.g. refrigeration or ammonia based $\mathrm{CO}_{2}$ capture processes. A possible approach to vapour suppression is via the addition of small amounts of alkali metal salts. Gibbs ensemble Monte Carlosimulations were used to study the effect of $0.5 \mathrm{~mol} \% \mathrm{NaCl}$ and $\mathrm{CsCl}$ on the VLE of $10 \mathrm{~mol} \%$ aqueous ammonia solutions. Sodium chloride and $\mathrm{CsCl}$ have been selected as two strategic representatives of the alkali metal series to demonstrate favourable interactions between cations and ammonia in aqueous solutions. The results of this study shed light on the influence of salts on thermodynamic properties as well as any solution structures that result from strong intermolecular interactions. Ions interact with ammonia molecules in the liquid phase through complex electrostatic interactions depending on species and composition. The simulations indicate that ammonia is preferentially located near $\mathrm{Na}^{+}$and $\mathrm{Cs}^{+}$. This is supported by the binding energies computed with $\mathrm{G} 4$ and M06-2X/RECPTZVPPD, which predict binding energies $\Delta G_{\text {bind }}\left(\mathrm{M}^{+}-\right.$ $\left.\mathrm{NH}_{3}\right)>\Delta G_{\text {bind }}\left(\mathrm{M}^{+}-\mathrm{H}_{2} \mathrm{O}\right)$ for $M=\mathrm{Li}-\mathrm{Cs}$ in the gasphase and $M=\mathrm{Li}-\mathrm{K}$ in the aqueous phase. These results also showed a decrease in the potential with increasing cation size from $\mathrm{Li}^{+}$to $\mathrm{Cs}^{+}$in the gas- and aqueous phase.

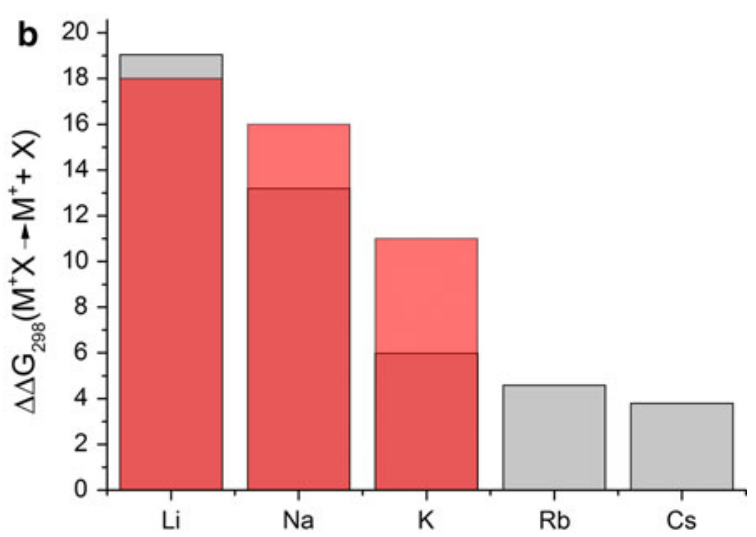

for the reactions $\mathrm{M}^{+}-\mathrm{NH}_{3} \rightarrow \mathrm{M}^{+}+\mathrm{NH}_{3}$ and $\mathrm{M}^{+}-\mathrm{H}_{2} \mathrm{O} \rightarrow \mathrm{M}^{+}+$ $\mathrm{H}_{2} \mathrm{O}$ at $T=298 \mathrm{~K}$ of $\left(\mathrm{M}^{+}=\mathrm{Li}^{+}\right.$to $\left.\mathrm{Cs}^{+}\right)$. The values obtained from calculations in the gas-phase are represented by gray-and the aqueous phase by semitransparent red bars

Gibbs ensemble Monte Carloalso shows that $\mathrm{NaCl}$ and $\mathrm{CsCl}$ have comparable effects on the solubility of ammonia, suggesting only a small dependence on the cation size. The results for densities obtained from the vapour liquid equilibrium are well reproduced by experiments within the temperature range approached by the experimental set-up used. In addition, the water-water $\mathrm{H}-\mathrm{H}$ RDF and the free energy of solvation of ammonia in the ammonia-water mixture are within the range of tabulated literature data.

Acknowledgments The authors gratefully acknowledge an allocation of CPU time from the NCI National Facility at the ANU and the HPSCC at Docklands. The authors also thank CSIRO Energy Technology for financial support.

Open Access This article is distributed under the terms of the Creative Commons Attribution License which permits any use, distribution, and reproduction in any medium, provided the original author(s) and the source are credited.

\section{References}

1. Kim DS, Infante Ferreira CA (2008) Solar refrigeration optionsa state-of-the-art review. Int J Refrig 31:3

2. D'Alessandro DM, Smith B (2010) Carbon dioxide capture: prospects for new materials. Angew Chem 49:6058

3. Lide DR (2009) CRC handbook of chemistry and physics, 90th edn. CRC Press, Boca Raton

4. Panagiotopoulos AZ (1987) Direct determination of phase coexistence properties of fluids by Monte Carlo simulation in a new ensemble. Mol Phys 61:813

5. Panagiotopoulos AZ, Quirke N, Stapleton M, Tildesley DJ (1998) Phase equilibria by simulation in the Gibbs ensemble: alternative derivation, generalization and application to mixture and membrane equilibria. Mol Phys 63:527

6. Ansell S, Barnes AC, Mason PE, Neilson GW, Ramos S (2006) $\mathrm{X}$-ray and neutron scattering studies of the hydration structure of alkali ions in concentrated aqueous solutions. J Biophysical Chemistry $124: 171$ 
7. Soper AK, Phillips MG (1986) A new determination of the structure of water at $25^{\circ} \mathrm{C}$. Chem Phys $107: 47$

8. Leberman R, Soper AK (1995) Effect of high salt concentrations on water structure. Nature 378:364

9. Botti A, Bruni F, Imberti S, Ricci MA, Soper AK (2004) Ions in water: the microscopic structure of a concentrated $\mathrm{HCl}$ solution. J Chem Phys 121:7840

10. Botti A, Bruni F, Imberti S, Ricci MA, Soper AK (2004) Ions in water: the microscopic structure of concentrated $\mathrm{NaOH}$ solutions. J Chem Phys 120:10154

11. McLain SE, Imberti S, Soper AK, Ricci MA, Bruni F, Botti A (2006) Structure of 2 molar $\mathrm{NaOH}$ in aqueous solution from neutron diffraction and empirical potential structure refinement. Phys Rev B 74:094201

12. Siepmann JI, Frenkel D (1992) Configurational-bias Monte Carlo: a new sampling scheme for flexible chains. Mol Phys 75:59

13. Martin MG, Siepmann JI (1999) Novel configurational-bias Monte Carlo method for branched molecules. Transferable potentials for phase equilibria. 2. United-atom description of branched alkanes. J Phys Chem B 103:4508

14. Chen B, Siepmann JI (2000) Improving the efficiency of the aggregation-volume-bias Monte Carlo algorithm. J Phys Chem B 104:8725

15. Chen B, Potoff JJ, Siepmann JI (2001) Monte Carlo calculations for alcohols and their mixtures with alkanes. Transferable potentials for phase equilibria. 5. United-atom description of primary, secondary and tertiary alcohols. J Phys Chem B 105:3093

16. Deng LY (2005) Efficient and portable multiple recursive generators of large order, ACM transactions on modeling and computer. Simulation 15:1

17. Berendsen HJC, Grigera JR, Straatsma TP (1987) The missing term in effective pair potentials. J Phys Chem 91:6269

18. Berendsen HC, Postma JPM, van Gunsteren WF, Hermans J (1981) In: Pullman B (ed) Interaction models for water in relation to protein hydration, in intermolecular forces. Reidel, Dordrecht, pp 331-342

19. Rizzo RC, Jorgensen WL (1999) OPLS all-atom model for amines: resolution of the amine hydration problem. J Am Chem Soc 121:4827

20. Hess B, van der Vegt NFA (2006) Osmotic coefficients of $\mathrm{NaCl}(\mathrm{aq})$ force fields. J Phys Chem B 110:17616

21. Aqvist J (1990) Ion-water interaction potentials derived from free energy perturbation simulations. J Phys Chem 94:8021

22. Lybrand TP, Ghosh I, McCammon JA (1985) Hydration of chloride and bromide anions: determination of relative free energy by computer simulation. J Am Chem Soc 107:7793

23. Allen MP, Tildesley DJ (1989) Computer simulation of liquids, 1st edn. Clarendon Press, New York

24. Ewald PP (1921) Die Berechnung optischer und elektronischer Gitterpotentiale. Ann Phys 63:253

25. McDonald IR (1972) NpT-ensemble Monte Carlo calculations for binary liquid mixtures. Mol Phys 23:41

26. Martin MG (2012) MCCCS Towhee. Available from http://towhee.sourceforge.net. Accessed 19 Jan 2012

27. Curtiss LA, Redfern PC, Raghavachari K (2007) Gaussian-4 theory. J Chem Phys 126:084108

28. Rappoport D, Furche F (2010) Property-optimized Gaussian basis sets for molecular response calculations. J Chem Phys 133:134105

29. Frisch, Trucks GW, Schlegel HB, Scuseria GE, Robb MA, Cheeseman JR, Scalmani G, Barone V, Mennucci B, Petersson GA, Nakatsuji H, Caricato M, Li X, Hratchian HP, Izmaylov AF, Bloino J, Zheng G, Sonnenberg JL, Hada M, Ehara M, Toyota K, Fukuda R, Hasegawa J, Ishida M, Nakajima T, Honda Y, Kitao
O, Nakai H, Vreven T, Montgomery JA Jr, Peralta JE, Ogliaro F, Bearpark M, Heyd JJ, Brothers E, Kudin KN, Staroverov VN, Kobayashi R, Normand J, Raghavachari K, Rendell A, Burant JC, Iyengar SS, Tomasi J, Cossi M, Rega N, Millam JM, Klene M, Knox JE, Cross JB, Bakken V, Adamo C, Jaramillo J, Gomperts R, Stratmann RE, Yazyev O, Austin AJ, Cammi R, Pomelli C, Ochterski JW, Martin RL, Morokuma K, Zakrzewski VG, Voth GA, Salvador P, Dannenberg JJ, Dapprich S, Daniels AD, Farkas Ö, Foresman JB, Ortiz JV, Cioslowski J, Fox DJ (2009) Gaussian 09. Gaussian, Inc, Wallingford

30. Schmidt MW, Baldridge KK, Boatz JA, Elbert ST, Gordon MS, Jensen JH, Koseki S, Matsunaga N, Nguyen KA, Su S, Windus TL, Dupuis M, Montgomery JA (1993) General atomic and molecular electronic structure system. J Comput Chem 14:1347

31. Zhao Y, Truhlar GD (2008) The M06 suite of density functional for main group thermochemistry, thermochemical kinetics, noncovalent interactions, excited states, and transition elements: two new functional and systematic testing of four M06-class functional and 12 other functional. Theor Chem Account 120:215

32. Leininger T, Nicklass A, Kuechle W, Stoll H, Dolg M, Bergner A (1996) The accuracy of the pseudopotential approximation: nonFrozen-Core effects for spectroscopic constant of alkali fluorides $\mathrm{XF}(X=\mathrm{K}, \mathrm{Rb}, \mathrm{Cs})$. Chem Phys Lett 255:274

33. Thompson JD, Windget P, Truhlar DG (2001) MIDIX basis set for the lithium atom: accurate geometries and atomic partial charges for lithium compounds with minimal computational cost. Phys Chem Comm 4:72

34. Bondi A, van der Waals (1964) Volumes and Radii. J Chem Phys 64:441

35. Kelly CP, Cramer CJ, Truhlar DG (2005) SM6: a density functional theory continuum solvation model for calculating aqueous solvation free energies of neutrals, ions, and solute-water clusters. J Chem Theory Comput 1:1133

36. Kelly CP, Cramer CJ, Truhlar DG (2006) Adding explicit solvent molecules to continuum solvent calculations for the calculation of aqueous acid dissociation constants. J Phys Chem B 110:2493

37. Higashi M, Marenich AM, Olson RM, Chamberlin A, Pu J, Kelly CP, Thompson JD, Xidos JD, Li J, Zhu T, Hawkins GD, Chuang Y-Y, Fast PL, Lynch BJ, Liotard DA, Rinaldi D, Gao J, Cramer CJ, Truhlar DG. GAMESSPLUS: a module incorporating electrostatic potential hessians for site-site electrostatic embedding, QM/MM geometry optimization, internal-coordinate-constrained cartesian geometry optimization, generalized hybrid orbital QM/ M methods, the SM5.42, SM5.43, SM6, SM8, SM8AD, and SM8 solvation models, the Löwdin and redistributed Löwdin population analysis methods, and the CM2, CM3, CM4, and CM4 M charge models into GAMESS. Users manual, version 2010-2. Available from http://comp.chem.umn.edu/gamessplus. Accessed 9 Sept 2012

38. Bryantsev VS, Diallo MS, Goddard WA III (2008) Calculation of solvation free energies of charged solutes using mixed cluster/ continuum models. J Phys Chem B 112:9709

39. Mähler J, Persson I (2012) A study of the hydration of the alkali metal ions in aqueous solution. Inorg Chem 51:425

40. Ohtaki H, Fukushima NJ (1992) A structural study of saturated aqueous solutions of some alkali halides by X-ray diffraction. Solution Chem 21:23

41. Jackson P (2004) Tandem mass spectrometry study of protonated methanol-water aggregates. Int J Mass Spectrom 232(1):67

42. Su T, Bowers MT (1979) Classical ion-molecule collision theory, vol.1, (chapter 3). In: Bowers MT (ed) Gas phase ion chemistry. Academic Press, New York, p 83

43. Yano YF (2005) Correlation between surface and bulk structures of alcohol-water mixtures. J Colloid Interface Sci 284:255 